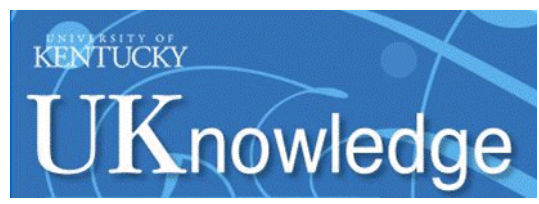

University of Kentucky

UKnowledge

\title{
"Okay Okay Okay, Now the Video Is On": An Analysis of Young Children's Orientations to the Video Camera in Recordings of Family Interactions
}

\author{
Sarah C. Barriage \\ University of Kentucky, sarah.barriage@uky.edu \\ Darcey K. Searles \\ Northeastern University
}

Follow this and additional works at: https://uknowledge.uky.edu/slis_facpub

Part of the Communication Commons, Family, Life Course, and Society Commons, Library and Information Science Commons, and the Quantitative, Qualitative, Comparative, and Historical Methodologies Commons

Right click to open a feedback form in a new tab to let us know how this document benefits you.

\section{Repository Citation}

Barriage, Sarah C. and Searles, Darcey K., "'Okay Okay Okay, Now the Video Is On": An Analysis of Young Children's Orientations to the Video Camera in Recordings of Family Interactions" (2019). Information Science Faculty Publications. 61.

https://uknowledge.uky.edu/slis_facpub/61

This Article is brought to you for free and open access by the Information Science at UKnowledge. It has been accepted for inclusion in Information Science Faculty Publications by an authorized administrator of UKnowledge. For more information, please contact UKnowledge@lsv.uky.edu. 


\title{
"Okay Okay Okay, Now the Video Is On": An Analysis of Young Children's Orientations to the Video Camera in Recordings of Family Interactions
}

\author{
Digital Object Identifier (DOI) \\ https://doi.org/10.18357/jcs00019172 \\ Notes/Citation Information \\ Published in Journal of Childhood Studies, v. 44, no. 3, p. 18-41. \\ Copyright @ 2019 Sarah Barriage, Darcey K. Searles
}

This work is licensed under a Creative Commons Attribution-NonCommercial 4.0 International License. 


\title{
"Okay Okay Okay, Now the Video Is On": An Analysis of Young Children's Orientations to the Video Camera in Recordings of Family Interactions
}

\author{
Sarah Barriage and Darcey K. Searles
}

\begin{abstract}
Sarah Barriage is an assistant professor in the School of Information Science in the College of Communication \& Information at the University of Kentucky. She recently completed her PhD in the School of Communication \& Information at Rutgers, The State University of New Jersey. Her research focuses on the everyday information practices of children and youth in diverse contexts, with a focus on child-centered methods of data collection and analysis. Email: sarah.barriage@uky.edu

Darcey K. Searles is a postdoctoral teaching associate in the Department of Communication Studies in the College of Arts, Media, and Design at Northeastern University. She recently completed her PhD in the School of Communication \& Information at Rutgers, The State University of New Jersey. Her research focuses on family interactions with young children in mediated and in-person contexts. Her recent work has examined shows in remote family Facetime conversations, as well as young children's updates in copresent family interactions. Email: d.searles@northeastern.edu
\end{abstract}

This paper explores 3- to 6-year-old children's orientations to the video camera in video recordings of everyday family interactions. Children's orientations to the video camera in these recordings were identified and analyzed using the constant comparative method. Types of orientations to the video camera included talking about the camera, engaging in cameradirected talk and/or action, and interacting with the camera. In some cases, these orientations occurred after a parent or sibling first oriented to the video camera; however, in other cases no prior orientation was evident. Theoretical and practical implications of the results are discussed.

Key words: early childhood; family interactions; qualitative research methods; participant reactivity; video recordings

using conversation analysis, the goals of which are to "describe the organization of ordinary social activities" ung cocial activities" (Sidnell \& Stivers, 2013, p. 33). As we began analyzing the video recordings collected for that study, we noted many instances of the children orienting to the video camera. Although not originally our research focus, we decided these instances of participant reactivity warranted further investigation.

\section{Literature review}

Researchers who use video recordings as a means of observing social interactions have noted many benefits of this technology in collecting and analyzing data. Video recordings are purported to provide a more detailed and accurate record of interactions than what could be obtained by a human observer (Knoblauch, Schnettler, \& Raab, 
2012). Recording interactions allows for repeated examination of talk and actions, affording the researcher the opportunity to examine minute details of the interaction (Heritage, 1989; Laurier \& Philo, 2006; Sidnell \& Stivers, 2013). Video recordings have also been cited as a means of increasing the reliability (Elder, 1999; Knoblauch et al., 2012), validity (Elder, 1999) and transparency (Heath, Hindmarsh, \& Luff, 2010) of research concerned with interpersonal interactions, because the raw data can be made available to and analyzed by others. This in turn increases opportunities for research collaborations, since multiple researchers can take part in intense observation of the same interactions (Heath et al., 2010). These benefits have caused some to call video recordings "the microscope of social science" (Aarsand, 2016, p. 91).

However, as with any method of data collection, naturalistic observation via video recordings is not without its drawbacks. One disadvantage associated with this method is that of participant reactivity (Heath et al., 2010). Specifically, the presence of recording equipment has the potential to influence the talk and actions of interactants, who may feel self-conscious or uncomfortable being recorded (e.g., Semeniuk \& Riesch, 2011; Speer \& Hutchby, 2003). As Speer and Hutchby (2003) note, this reactivity causes some researchers to call into question whether recorded interactions can be considered natural or authentic reflections of everyday interaction. Worries about participant reactivity have led some to conclude that natural interactions are impossible to capture via video or audio recording, because the very introduction of recording equipment and resulting participant reactivity fundamentally change the nature of the interaction (Lomax \& Casey, 1998; Speer \& Hutchby, 2003). Conversely, other researchers contend that participant reactivity is "often exaggerated" (Heath et al., 2010, p. 48), with participants' awareness of the video camera occurring primarily at the onset of recording and subsiding once participants become accustomed to its presence (Heath et al., 2010; Knoblauch et al., 2012). These researchers argue "that within a short time, the camera is 'made at home" (Heath et al., 2010, p. 49), with minimal impact on the authenticity of the recorded interactions (Lomax \& Casey, 1998; Rosenstein, 2002).

In research with adults, there is much variability in reported frequency and duration of participant orientations to the video camera, as well as variability in the ways adult participants orient to the camera (Heath et al., 2010). For example, Heath et al. (2010) noted in their work that participants' orientations to the video camera occurred in "occasional moment[s] of awareness" (p. 48), such as when recording commenced, when a new participant entered the room, or during lulls in activity. In medical settings, adult orientations to the video camera were more likely to occur at the beginning of the interaction, as well as when the physician was out of the room (Penner et al., 2007). These orientations to the video camera were both infrequent and short in duration (Penner et al., 2007). Ways in which adults orient to the presence of recording equipment include looking at the camera (Laurier \& Philo, 2012; Penner et al., 2007), waving and making faces at the camera (Laurier \& Philo, 2012), gesturing to the camera (Penner et al., 2007), and talking about the recording equipment (Penner et al., 2007; Speer \& Hutchby, 2003).

Similar variability is evident in the small body of research concerned with participant reactivity in children. For example, some researchers assert that children typically only attend to the video camera when recording commences and quickly resume normal activities, but do not provide empirical evidence for this assertion nor specify the age range of the children on which their assertions are based (e.g., Häggman-Laitila, Seppänen, Vehviläinen-Julkunen, \& Pietilä, 2010; O’Shannessy, 2014; Rosenstein, 2002). Other researchers have been more specific about the participant reactivity encountered in their research with children. For example, Antal et al. (2015) reported that children oriented to the video camera at least once in $74 \%$ of their recordings of visits with pediatric health care providers. Children displayed more orientations to the camera than did their parents or health care providers, with 5- to 7-year-old children displaying orientations six times more often than children over age 13 (Antal et al., 2015). Overall, these orientations made up a very small proportion of the total behaviours coded by the researchers (Antal et al., 2015). Talking about the recording equipment was the most frequent type of 
orientation to the camera displayed by children in this study (Antal et al., 2015), and has been identified in other studies with children between 3 and 8 years of age (e.g., Given et al., 2016; Speer \& Hutchby, 2003). Other types of orientations to the camera identified in prior research include staring or briefly glancing at the camera, waving or pointing at the camera, and performing for the camera (Antal et al., 2015; Given et al., 2016).

In research with both children and adults, most systematic, empirical considerations of participant reactivity draw on video recordings of medical interactions (e.g., Antal et al., 2015; Penner et al., 2007). There is little evidence of such investigations focused on the reactivity of young children in studies using video recordings of family interactions in the home, with discussions of participant reactivity in such settings including assertions that such reactivity was minimal (e.g., Häggman-Laitila et al., 2010) or considered as one of several challenges encountered in home-based video recordings (e.g., Given et al., 2016). As such, there remain many unanswered questions about the reactivity of young children in this setting, including the prevalence of participant reactivity, the types of behaviours displayed when such reactivity occurs, and the events precipitating participant reactivity. The current study addresses these gaps.

\section{Research questions}

This paper explores young children's orientations to the video camera during video recordings of everyday family interactions. Specifically, this paper seeks to address the following questions about the talk and actions of 3- to 6-year-old children:

1. How prevalent were the children's orientations to the video camera?

2. In what ways did the children orient to the video camera?

3. What, if anything, preceded the children's orientations to the video camera?

\section{Method}

\section{Participants}

Video recordings of family interactions were collected from 20 families with at least one child 3-6 years of age. Participants were recruited from the northeastern United States and southern Ontario, Canada, by posting flyers in local libraries, university buildings, businesses, and daycare centres. Snowball sampling was also used.

A total of 23 children (14 girls and 9 boys) in the target age range $(M=4.26$ years, $S D=1.18)$ participated in this study, as well as the children's parent(s) and/or sibling(s). In four families, the child in the target age range was an only child; in three families, both children were in the target age range; in four families, the target child had a sibling under 2 years of age; and in nine families, the target child had one or more older siblings. The youngest sibling in this data was eight months and the oldest 17 years of age. In all but one family, a parent (typically the mother) was present in at least one of the video recordings.

\section{Data collection}

Parents were provided with two black Flip Ultra Pocket Camcorders ( $2^{\text {nd }}$ generation), which are $6 x 3$ inches in size, include a playback screen, and can be attached to a small tabletop tripod for stability. Parents were also given a checklist of suggested steps for obtaining quality video recordings (such as ensuring the television or radio was not playing in the background, and that all interactants could be seen in the video) and a list of potential interactions that might be communication rich, such as mealtimes, playtimes, and bedtime routines. Parents were asked to use 
the video cameras to record three interactions lasting 30-60 minutes that included their child(ren) in the target age range and at least one other family member.

A total of 100 videos were collected from these 20 families, totalling 30 hours 42 minutes 20 seconds. The video recordings averaged 18 minutes 25 seconds in length, with each family recording an average of 92 minutes 7 seconds of video. Some families completed more than the requested three video recordings. Reasons cited by the parents for additional recordings included the video cameras shutting off mid-recording, either inadvertently due to issues with the camera battery or the record button being hit, or purposefully, such as when a child needed to use the bathroom, as well as concerns about providing the researchers with communication-rich interactions long enough in duration to satisfy the research purposes.

A variety of interactions was captured in these recordings, with the children and their families engaging in play, eating and preparing meals, reading stories, engaging in bedtime routines, completing homework, and participating in arts and crafts. Most families recorded videos in their homes; one family completed the video recordings at their church, and one family completed one video recording in their vehicle. In the majority of the video recordings, parents placed the camera in a fixed position (Heath et al., 2010), at times adjusting the angle of the camera or moving the camera to another location. In other recordings, parents elected to make use of what Heath et al. (2010) term the "roving camera" approach, following their children with the camera as they engaged in activities in various locations in their homes.

\section{Data analysis}

All video data were coded by the researchers for instances of orientation to the video camera exhibited by the children in the target age range. Orientation to the video camera was defined as any instance in which a child explicitly displayed through their talk or their actions that they were aware of the presence of the video camera. Instances in which children simply glanced in the direction of the video camera were not included in this analysis, since the researchers were not present during the recordings, it was not possible to determine if the child was indeed looking at the video camera or if they were looking at a person or object located behind or near the camera. An instance of an orientation to the video camera was considered to begin when a child displayed his or her awareness of the video camera and was considered to end when the child engaged in some other talk or action that was unrelated to the presence of the video camera. The video recordings collected from one family included three short videos during which the parents allowed their child the opportunity to use the video cameras and tripods in order to understand how the equipment worked. These three videos were omitted from subsequent analyses of the children's orientations to the video camera, because interaction with the video camera was the primary focus of these three recordings.

The family ID number, video name, timestamp, child's pseudonym, age, and gender were recorded for each instance of a child's orientation to the video camera. The presence of parent(s) and/or sibling(s) was also noted. Each instance of a child's orientation to the video camera was transcribed using the Jeffersonian transcription system (Hepburn \& Bolden, 2017) and then analyzed inductively using the constant comparative method (Glaser \& Strauss, 1967), with an initial open coding scheme developed based on the talk and actions displayed by the children, followed by axial coding. Each orientation could be composed of a single or multiple types of talk and/ or action, and each of these were coded for every orientation. Each instance was also analyzed to identify any talk or action related to the presence of the video camera displayed by the child's parent(s) or sibling(s) prior to, after, and during the child's orientation to the camera. 


\section{Findings}

\section{Prevalence of orientations to the video camera}

A total of 102 instances of young children orienting to the video camera were identified in the video recordings analyzed for this study. The average number of orientations per child was $4.43(S D=4.71)$, with 17 of 23 children (73.91\%) orienting to the video camera at least once. As Rideout (2014) notes, "averages mask big differences" in the behaviours of individual children (p. 11); in our data, six children did not display any orientation to the video camera in any of the recordings collected from their families, while one child displayed 18 orientations to the video camera. Orientations to the video camera averaged 21 seconds in length ( $S D=23$ seconds). The longest orientation was 1 minute 51 seconds, and the shortest 1 second. For children who did orient to the video camera, the average total time each child oriented to the camera across all recordings was 2 minutes 16 seconds $(S D=1$ minute 50 seconds), with a minimum total time spent orienting to the camera of 2 seconds and a maximum total time of 6 minutes 59 seconds.

Orientations to the video camera did not occur in every video recording. Specifically, in 58 of the 97 (59.79\%) videos, there were no instances of the child(ren) in the target age range orienting to the video camera. The number of times a child oriented to the video camera in the remaining 39 videos is displayed in Figure 1.

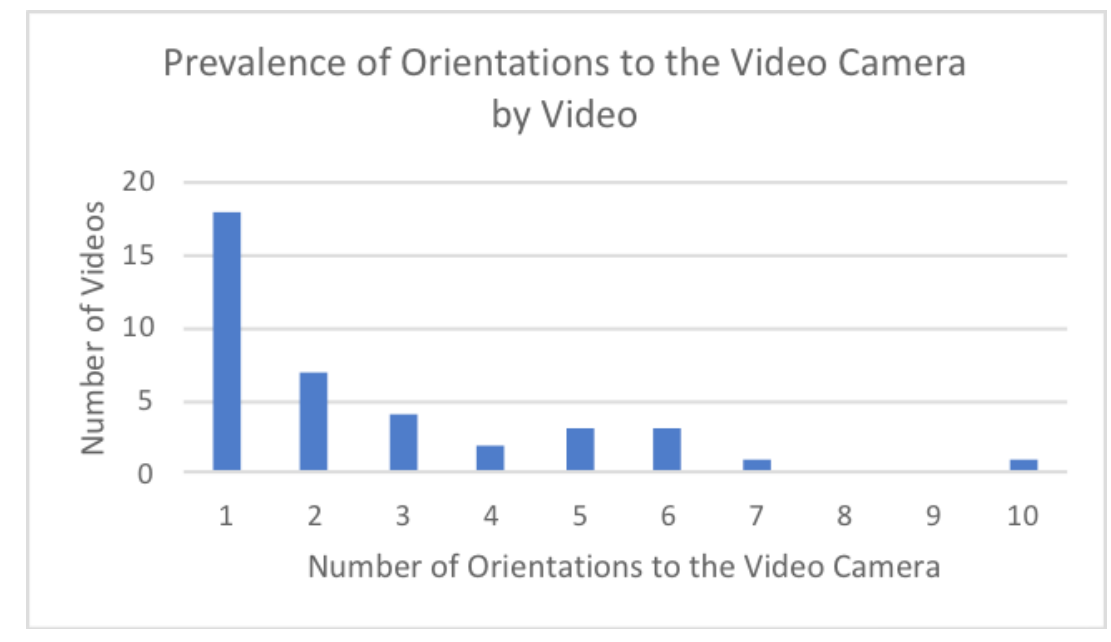

Figure 1. Frequency of orientations to the video camera by video.

\section{Types of orientation to the video camera}

The children oriented to the video camera using three main types of talk and/or action: they talked about the camera, engaged in camera-directed talk and/or action, and interacted with the camera (see Table 1). Each of these three types of orientation to the video camera consists of similar subtypes of talk and/or action that are related to the video camera. For example, the "camera-directed talk/actions" type of orientation includes such subtypes of talk and/or action as talking to the camera, singing, making faces, putting one's face or an object close to the camera, waving, and dancing. Each instance of a child's orientation to the video camera could include any number and type of these orientations, and so the totals given in Table 1 should not be considered summative. 
Table 1

Types of Children's Orientations to the Video Camera

\begin{tabular}{|c|c|c|}
\hline Type of Orientation & Description of Orientation & $\begin{array}{l}\text { Number of } \\
\text { Orientations }\end{array}$ \\
\hline Talks about camera & & 77 \\
\hline Mentions camera & $\begin{array}{l}\text { says something or asks about the camera } \\
\text { (including embodied actions) }\end{array}$ & 68 \\
\hline Mentions research & $\begin{array}{l}\text { says something about the research or the } \\
\text { researcher(s) }\end{array}$ & 6 \\
\hline Asks to watch video & asks to watch the video recording & 3 \\
\hline Camera-directed talk/actions & & 75 \\
\hline Talks to camera & says something to/for the camera & 25 \\
\hline Sings & sings to/for the camera & 14 \\
\hline Makes faces & makes faces to/for the camera & 13 \\
\hline Puts face close to camera & puts face near the camera lens & 9 \\
\hline Puts object in front of camera & puts object in front of camera lens & 7 \\
\hline Waves & waves to/for the camera & 4 \\
\hline Dances & dances to/for the camera & 3 \\
\hline Interacts with camera & & 40 \\
\hline Looks in viewfinder & looks through the camera's viewfinder & 16 \\
\hline Looks at self in viewfinder & $\begin{array}{l}\text { puts part of own body (e.g., arm, hand) } \\
\text { in front of camera lens while looking } \\
\text { through viewfinder }\end{array}$ & 6 \\
\hline Commentary & $\begin{array}{l}\text { talks about what is seen through } \\
\text { viewfinder }\end{array}$ & 5 \\
\hline Moves camera & moves camera to another location & 5 \\
\hline Touches camera & touches camera (without moving it) & 5 \\
\hline Adjusts camera & $\begin{array}{l}\text { adjusts camera angle/positioning (without } \\
\text { moving it) }\end{array}$ & 3 \\
\hline Other & & 3 \\
\hline
\end{tabular}


Each of the three main types of orientation to the video camera identified in the data is described below, with the clearest examples of several of the subtypes provided.

Talks about camera. The most frequent type of orientation to the video camera was when the children talked about the camera (77 orientations). This type of orientation includes talk and/or action about the camera, such as mentioning the camera, mentioning the research project and/or the researcher, and asking to watch the video recording currently being generated.

Within this type of orientation, and overall by far the most frequent child-displayed orientation to the camera, were those in which the child mentions the camera. In these instances, the child says something or asks about the camera, indicating their awareness of the presence of the video camera. For example, in extract 01, Abby ${ }^{1}(5)$ and Libby (3) are playing a game with their mom. Abby orients to the camera with, "okay okay oka:y.hhh now the video:: is o::.: n." (lines 10,13) after Mom has moved towards the camera (lines 06-08) and is adjusting it (line 11).

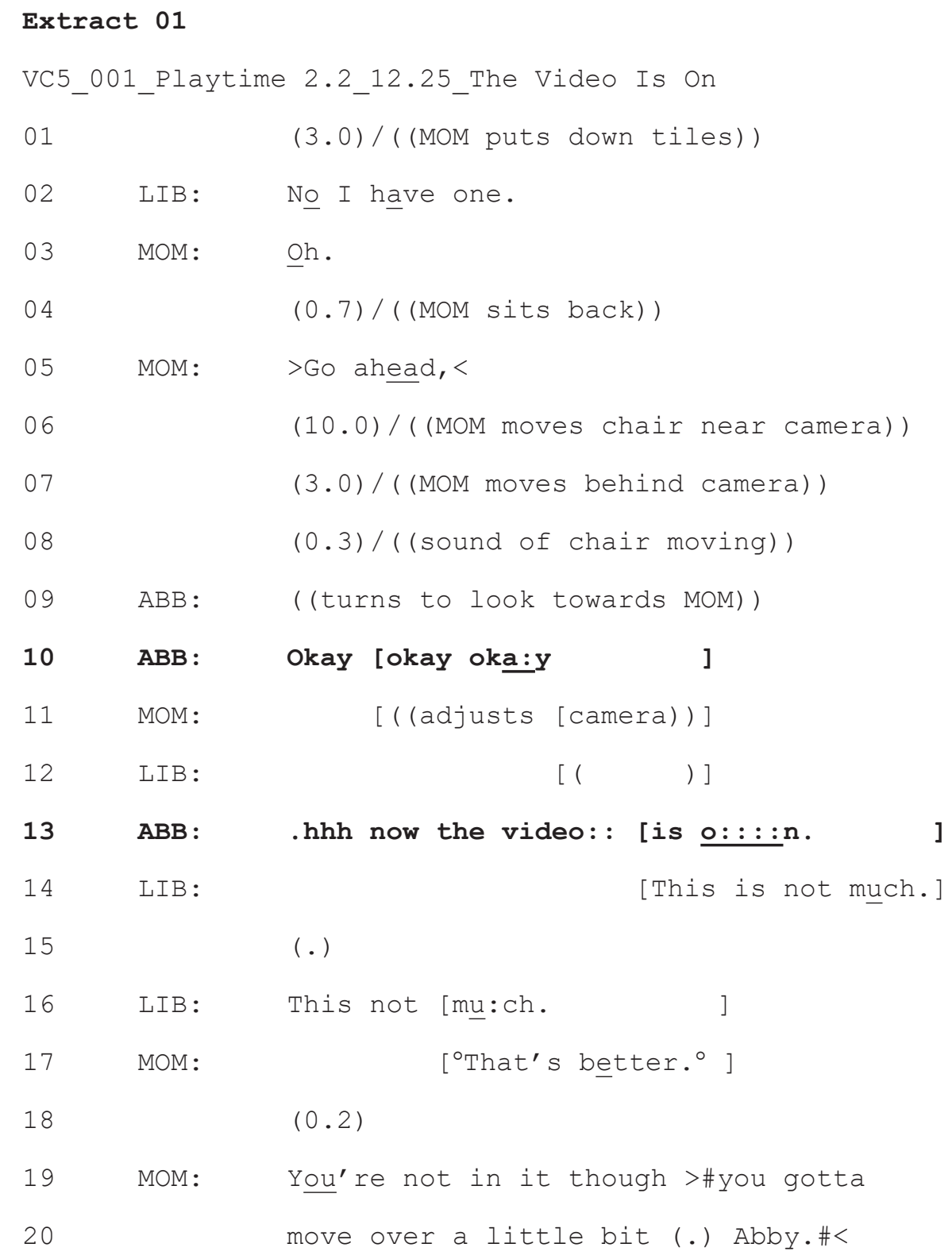

MOM : 
This orientation to the camera occurs after Mom has gotten up and moved a chair behind the camera out of view (lines 06-08). In line 08 the chair makes a noise and Abby then turns to look at the source of the noise (and thus at Mom and the camera; line 09). Abby then says "okay okay oka:y .hhh now the video:: is o.:.:n." With this turn Abby announces the presence (and activity) of the camera recording. Additionally, in overlap with Abby's line 10, Mom adjusts the camera view. Here, Abby's orientation to the camera is prompted by Mom's actions (approaching the camera and adjusting the camera). Abby's orientation simply mentions the camera: by announcing that the camera is on she shows her awareness of the camera's placement as well as that it is currently recording her.

Within the orientation type of "talks about camera," there are also instances in which the child asks to watch the video that is currently being recorded, and those in which he or she says something about the research or the researcher, including greeting one of the researchers by name. These orientations also demonstrate children's emerging and ongoing awareness of the video camera and its function, including their understanding that the video recordings can later be viewed by both themselves and others.

Camera-directed talk/actions. The second most frequent type of orientation to the camera was "camera-directed talk/actions" (75 orientations). In these instances, the children's orientations to the camera exemplify how the presence of the video camera may affect these everyday interactions in that the children are performing something specifically for the camera, most often by doing something silly and/or funny, such as singing or making faces. In these instances, the orientations consist of talk and/or action that appear to be performed for the camera itself.

Within this orientation type, the most common subtype were those instances in which the child talks to the camera, such as telling the camera about his/her action(s) or information about him/herself. In extract 02 , Mom has just turned on the video camera (it is stationary) and Eddie (7) and Timmy (5) are eating breakfast. In lines 02 to 04 Timmy looks directly at the camera and says, "Hello, we're eating breakfast and thịs is French toast" as he holds up a piece of French toast (see Figure $2^{2}$ ).

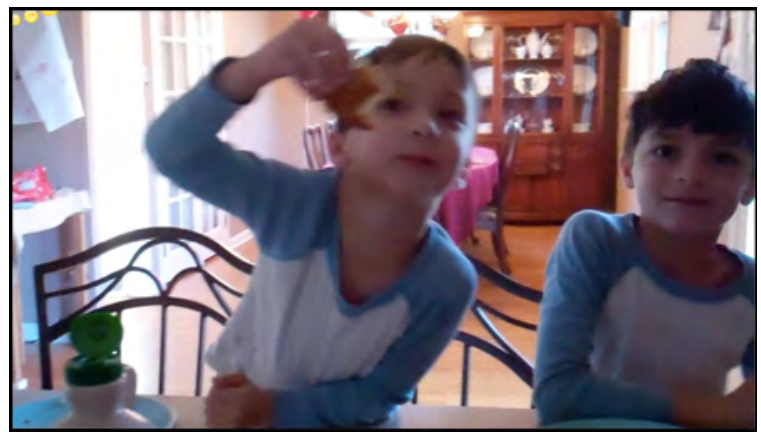

Figure 2. Timmy talks to the camera and puts an object in front of the camera lens.

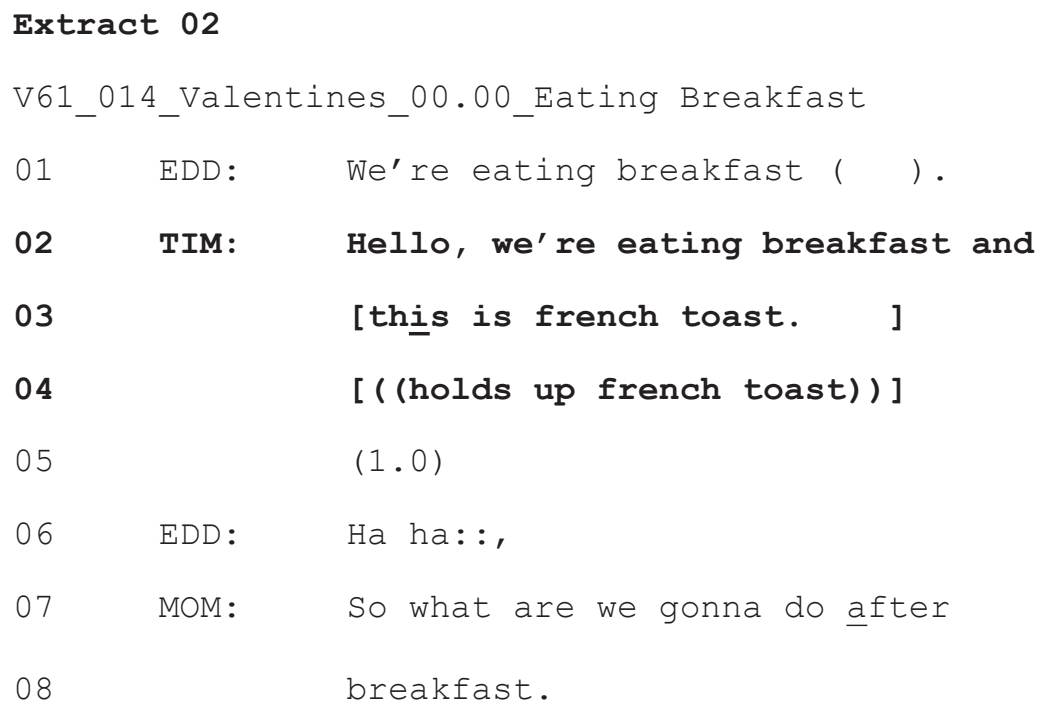

In this extract, we can see that Timmy announces what he is doing for the camera. He greets the camera with "hello" and then states what he is doing (eating breakfast) as well as what he is eating (French toast; lines 02-04), 
providing a commentary ${ }^{3}$ (Heritage \& Stivers, 1999) of his current ongoing activities. In this subtype of orientation to the video camera, the child is doing something specifically for the camera, either describing ongoing activities or, as in other instances, explaining why something has happened.

Another example of camera-directed talk and/or actions occurs in extract 03, where Amanda (6) and Nathan (10) are working together to make a blanket. In lines 05 to 06 Amanda puts her face close to the camera lens, makes faces towards the camera and sings loudly.

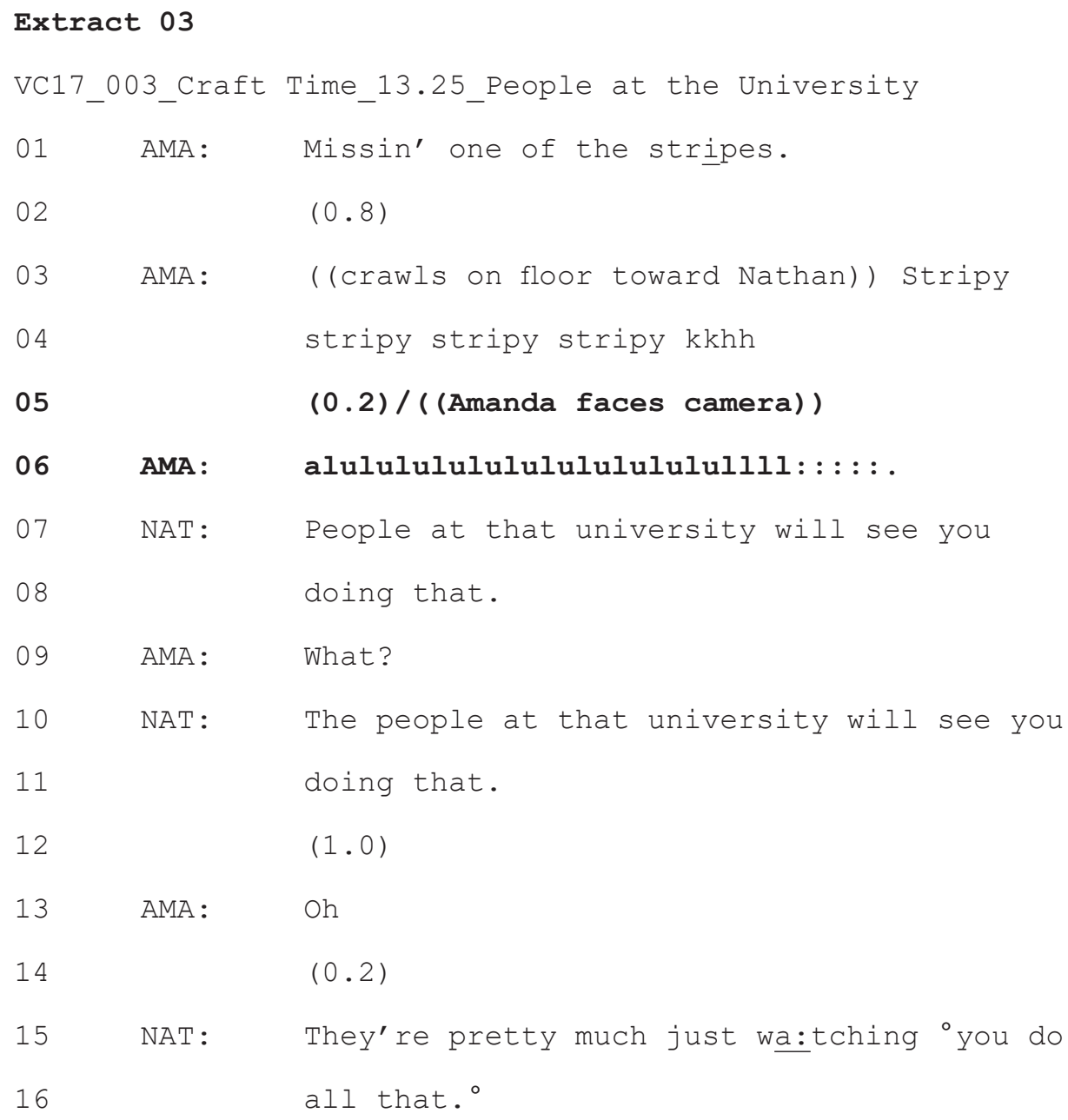

Here we can see how Amanda transitions from the ongoing activity of making the blanket (lines 01-03) to an orientation to the camera that becomes an activity in and of itself. These orientations are not relevant in the course of Amanda and Nathan's ongoing activity (i.e., making the blanket), but are directed towards the camera and not any co-present person. Thus, they truly are directed towards the camera, and it is possible to see how the presence of the video camera has the potential to impact children's everyday interactions. Although we cannot know if Amanda would have danced, made faces, or sang without the presence of the video camera, it is clear that these orientations are directed specifically to the camera itself. ${ }^{4}$

Interacts with camera. The third most frequent type of orientations to the video camera are those in which the child "interacts with the camera" (40 orientations). In these instances, the child manipulates the camera in some 
way, by either physically handling it or looking through the viewfinder. In extract 04 Eden (4), Mom, Julie (8), and Lucas (10) are having dinner while Lucas does his homework. In line 09, Eden looks in the camera's viewfinder and issues commentary on what she can see through the viewfinder.

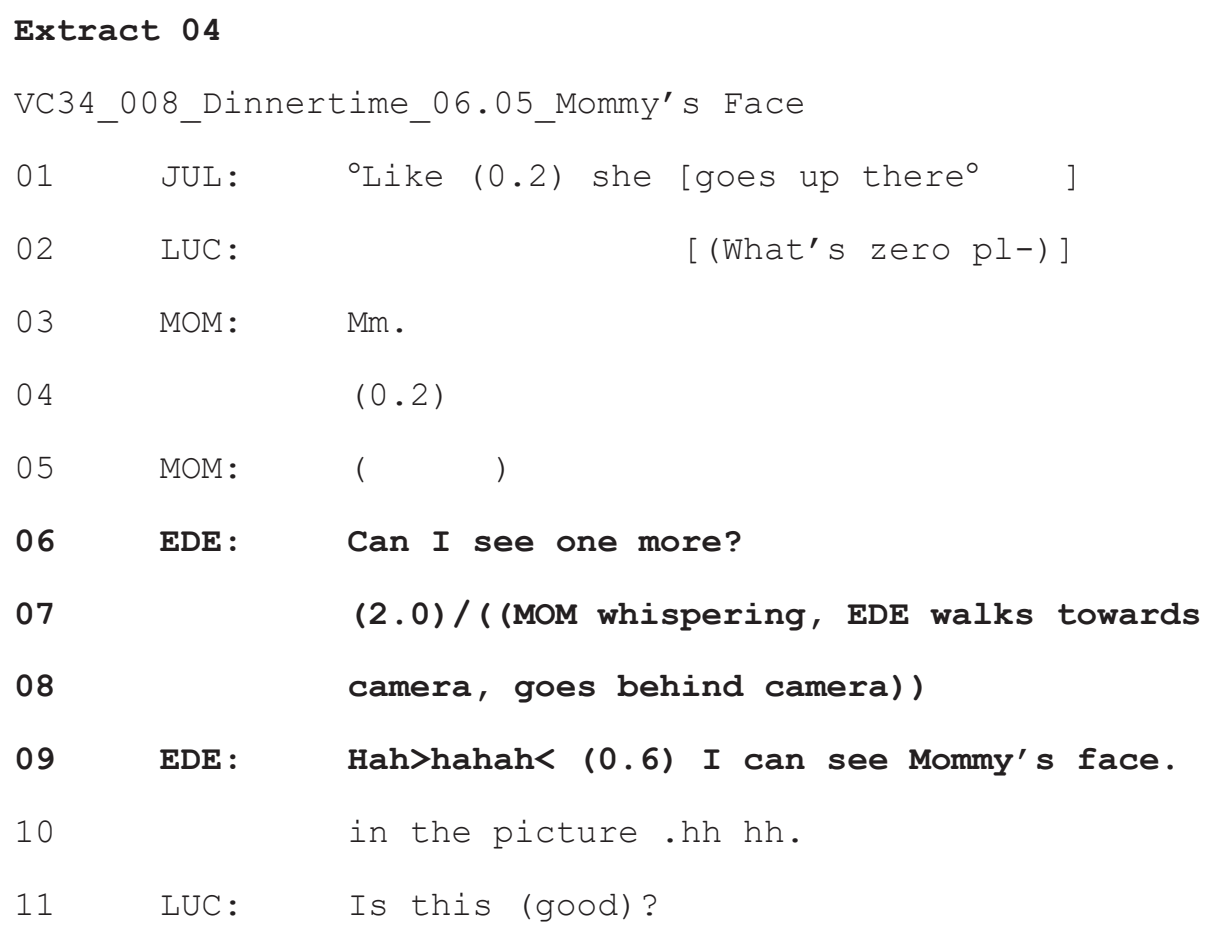

At the beginning of this segment Julie is "telling" on Eden for having touched the camera a few minutes before (line 01), which Mom responds to with a minimal "mm." (line 03), thereby not taking up Julie on her previous turn. Eden then requests permission to look at the camera again with "Can I see one more?" (line 06). She does not wait for permission from Mom, but then walks towards the camera (line 08) and then provides a commentary (Heritage \& Stivers, 1999) of what she can see with "Hah>hahah< (0.6) I can see Mommy's face." while presumably looking through the viewfinder of the camera (line 09). Here we can see how children's orientations to the camera can be focused on how the camera works, including what the camera can and cannot see. When Eden goes to look behind the camera, what is pertinent to her, and what she announces to the others, is what she can see by looking through the camera's viewfinder.

Within this type of orientation are also several subtypes in which children physically manipulate the camera in some way. In extract 05, Lacey (4) and her mom have been making crafts and now Mom is preparing lunch. Lacey adjusts the camera angle in line 12 .

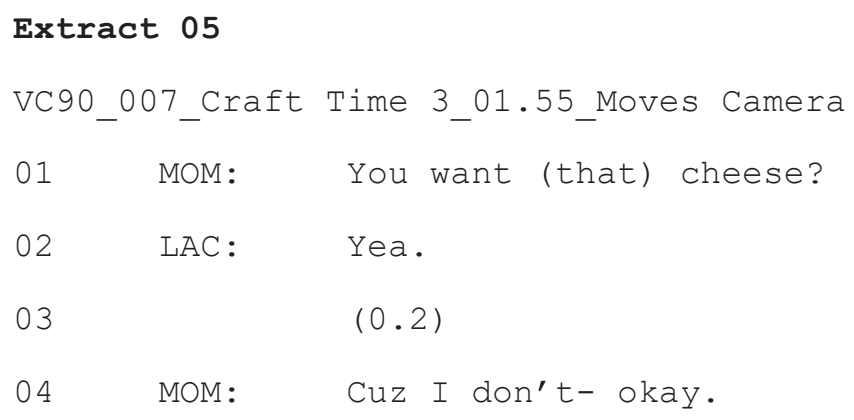




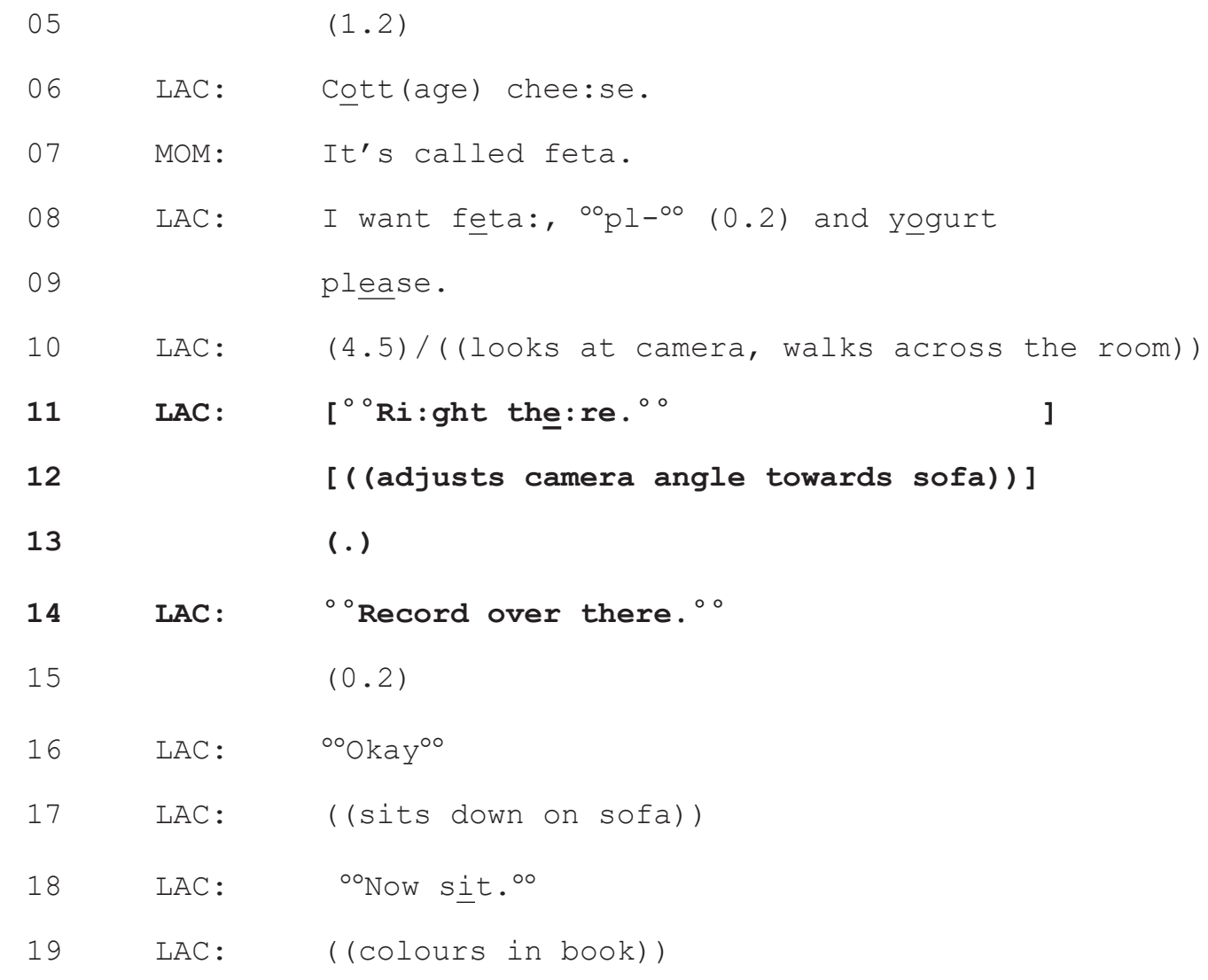

After they discuss what Lacey will eat (lines 01-09), Lacey looks at the camera (line 10), walks across the room and then towards the camera (line 10). She then adjusts the camera angle towards the sofa (line 12) as she whispers

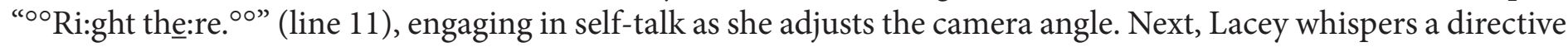
to the camera with "००Record over there. ${ }^{\circ}$ " (line 14) and then "o०Okay "०" (line 16; presumably treating the camera angle as now being sufficient) and sits down on the sofa (line 17), talking to herself with "००Now sit. ${ }^{\circ 0 "}$ (line 18). Here we can see how Lacey's orientation to the video camera demonstrates an awareness of both the fact that she is being recorded as well as the limitations of the video camera (it can only record what is in front of the lens). By adjusting the angle of the camera so it is focused on the sofa, she is then able to complete her activity in the view of the camera (see Figure 3).
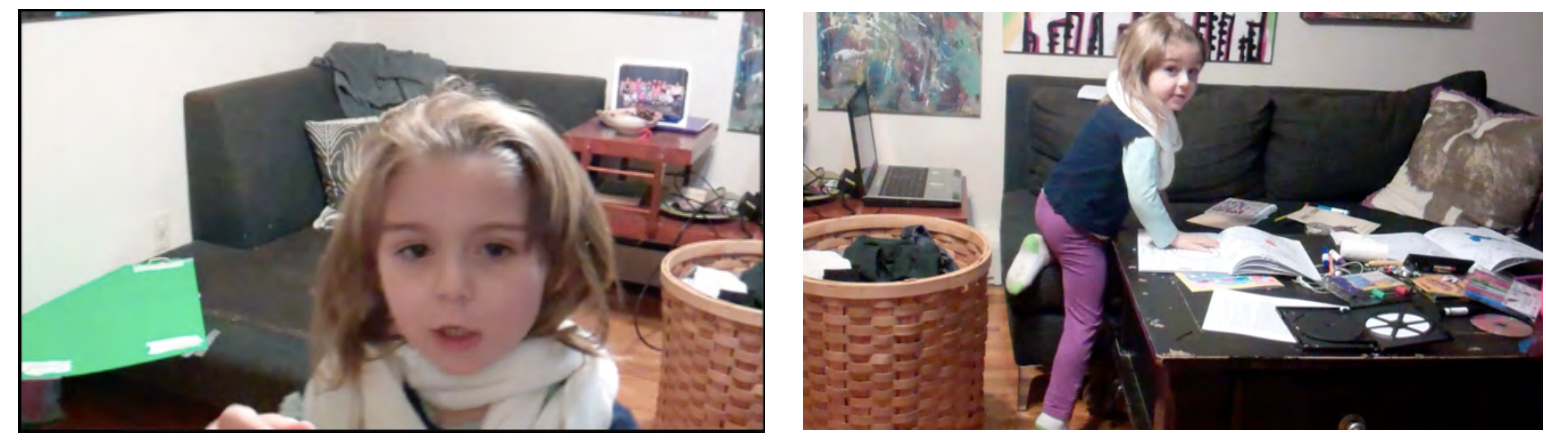

Figure 3. Lacey adjusts the camera (left), then sits on sofa while checking camera angle (right).

When the children orient to the video camera by interacting with it, they demonstrate their awareness of the camera's presence and, in some cases, its limitations. By moving and/or adjusting the camera to ensure that it 
captures a particular scene, children not only show they are aware that their current actions are displayed to the camera, but also that the camera might not capture everything. When the children look through the viewfinder, they are also interacting with the camera's capabilities by attempting to see what it sees.

Other. Finally, there were three orientations to the video camera that did not fit within the three types of orientations identified in the data. Since there were so few of these instances, and they were dissimilar to the other orientations, they were not included in the typology.

\section{Others' talk and action preceding children's orientation to the video camera}

In 64 of the $102(62.75 \%)$ instances of a child's orientation to the video camera, a parent and/or sibling first oriented to the video camera in some way. These orientations appear to have brought the video camera to the forefront of interactions and thus triggered the children's orientation to the camera, much as how something someone says may trigger a subsequent story by another interlocutor (Jefferson, 1978). That is, with these orientations, there is a clear prior orientation to the video camera by another participant that then brings about the child's own orientation.

Sibling orientations. Siblings oriented to the camera in very similar ways as the children in the target age range: talking about the camera, interacting with the camera, and engaging in camera-directed talk/action (see Table 2).

Table 2

Types of Sibling Orientations to the Camera Preceding Child's Orientation

\begin{tabular}{lll}
\hline Types of Orientation & Description of Orientation & $\begin{array}{l}\text { Number of } \\
\text { Orientations }\end{array}$ \\
\hline Talks about camera & says something about the camera & 8 \\
\hline Mentions camera & & 8 \\
\hline Interacts with camera & looks through the camera's viewfinder & 3 \\
\hline Looks in viewfinder & moves camera to another location & 2 \\
\hline Moves camera & $\begin{array}{l}\text { adjusts camera angle/positioning (without } \\
\text { moving it) }\end{array}$ & 2 \\
\hline Adjusts camera & & 3 \\
\hline Camera-directed talk/action & says something to/for the camera & 2 \\
\hline Talks to camera & puts face near the camera lens & 1 \\
\hline Puts face close to camera & sings to/for the camera & 1 \\
\hline Sings & & 2 \\
\hline Other & & 2 \\
\hline
\end{tabular}

Parent orientations. Parents also exhibited the same three main types of orientation to the video camera. They engaged in similar talk and actions as their children, such as adjusting the camera, moving the camera, mentioning the camera, mentioning the research study, and waving to the camera (see Table 3). However, parents 
also displayed orientations to the video camera that were not exhibited by the children in the target age range. These included using a roving camera approach to recording, turning on the camera, approaching the camera, and issuing directives to their children related to the presence of the video camera. The orientation types that are unique to parents are discussed below.

Table 3

Types of Parent Orientation to the Video Camera Preceding Child's Orientation

\begin{tabular}{lll}
\hline Types of Orientation & Description of Orientation & $\begin{array}{l}\text { Number of } \\
\text { Orientations }\end{array}$ \\
\hline Interacts with camera & $\begin{array}{l}\text { adjusts camera angle/positioning (without } \\
\text { moving it) }\end{array}$ & 16 \\
\hline Adjusts camera & moves camera to another location & 14 \\
\hline Moves camera & holds camera while recording & 8 \\
\hline Roving camera & begins video recording & 5 \\
\hline Turns on camera & moves toward camera & 3 \\
\hline Approaches camera & & 29 \\
\hline Talks about camera & $\begin{array}{l}\text { issues directive to child related to presence of } \\
\text { video camera }\end{array}$ & 16 \\
\hline Directive & says something about the camera & 11 \\
\hline Mentions camera & says something about the research study & 2 \\
\hline Mentions research & & 3 \\
\hline Performs for camera & waves to/for the camera & 2 \\
\hline Waves to camera & says something to/for the camera & 1 \\
\hline Talks to camera & & \\
\hline
\end{tabular}

Interacts with camera. In the orientation type "interacts with camera," parents exhibited three subtypes of talk and action that were not exhibited by the children within the target age range: using a roving camera approach, turning on the camera, and approaching the camera.

The roving camera approach involved the parent following the child with the video camera, as opposed to setting the camera on a stable surface to record. In extract 06, Mom follows Zara (4) with the video camera as she leaves the kitchen / dining room area and goes to the bathroom to wash her hands. 


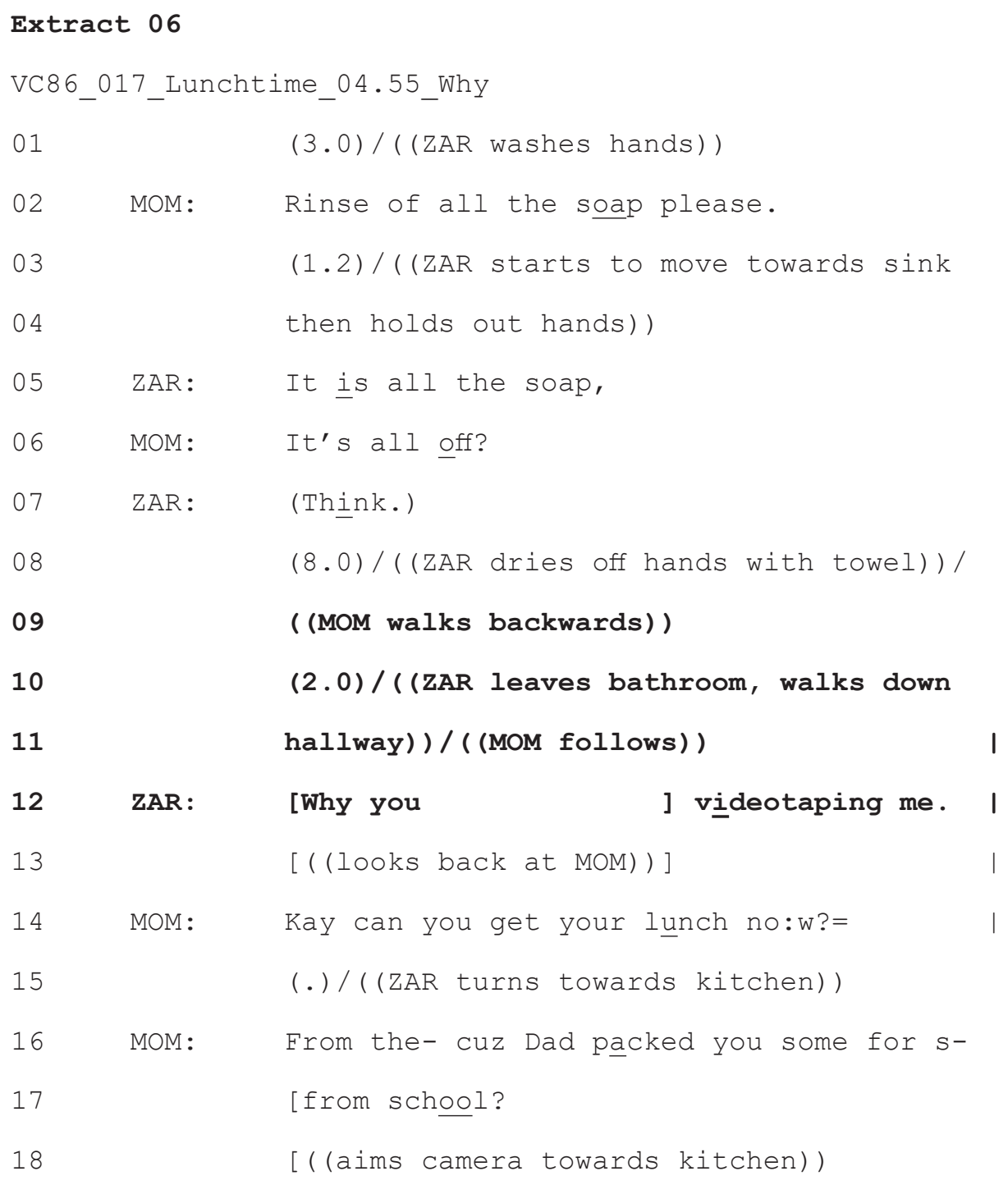

In lines 01-07, Zara washes her hands at the bathroom sink while Mom stands in the doorway holding the camera. In line 08, Zara moves from the sink to dry her hands with a towel, and Mom moves backward in order to keep Zara in the frame of the camera (line 09). In line 10 Zara leaves the bathroom and walks down the hall, and Mom follows her with the camera (line 11). In lines 12-13, Zara looks back at Mom, who is still holding the camera, and asks "Why you videotaping me." Mom does not answer Zara's question, but instead in line 14 prompts her with the request, "Kay can you get your lunch no:w?=", sequentially deleting Zara's inquiry and attempting to move her back into ordinary activities. Zara then moves toward the kitchen in line 15 as Mom specifies her request in lines 16-17, aiming her camera towards the kitchen (line 18). In this extract, we can see how Mom's interaction with the camera precedes Zara's orientation. It is Mom's roving camera approach that appears to trigger Zara's orientation to the video camera.

Children also orient to the camera after a parent turns it on. In extract 07, Mom turns on the camera (line 01) and Walter (3) subsequently orients to it (lines $04,10,12,14,19,21$ ). 


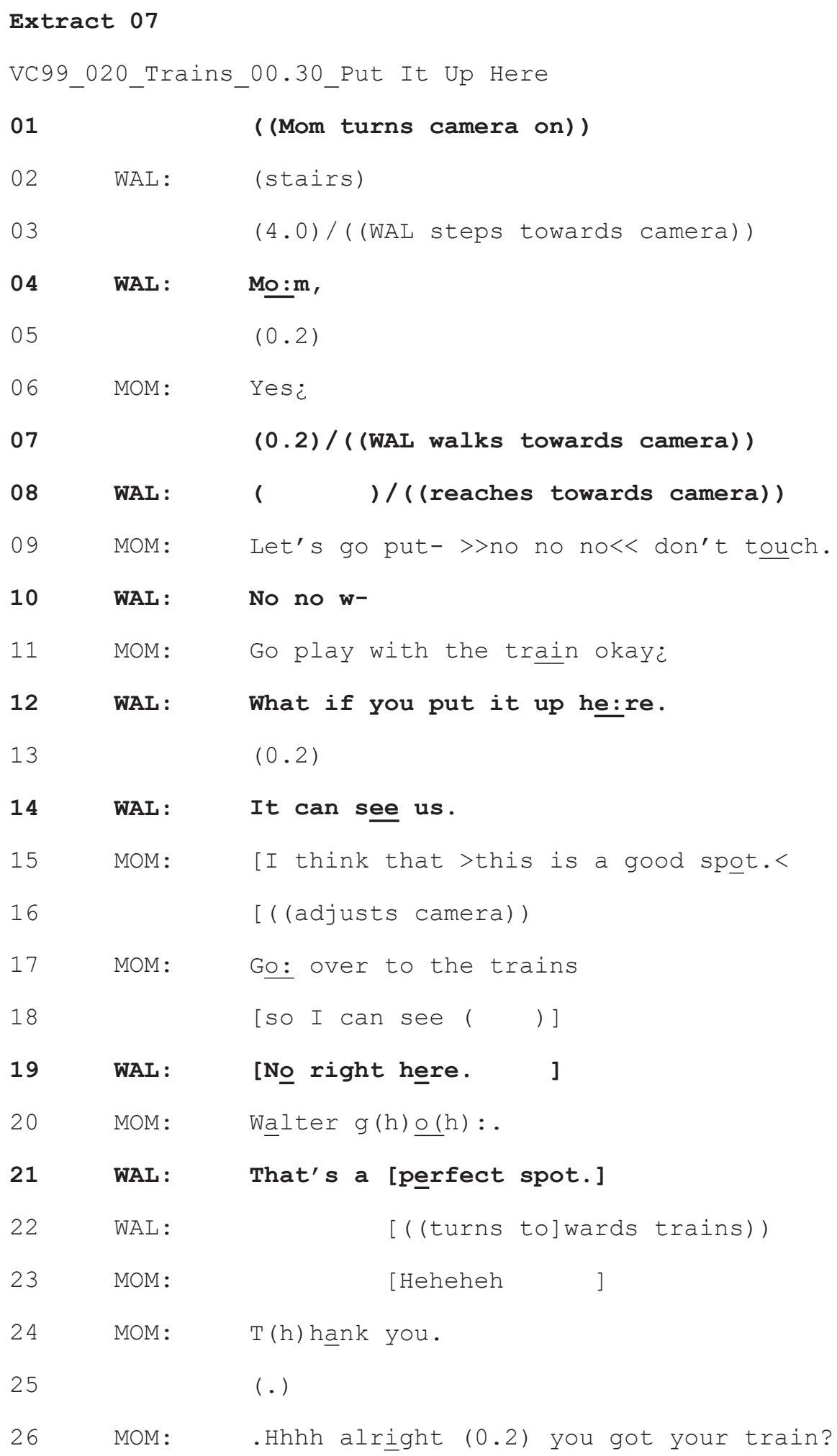

Walter's orientation to the camera starts in line 04 when he summons his mom, "Mo:m," Mom responds with "Yes ¿" (line 06) and Walter then walks towards and reaches for the camera (lines 07-08; see Figure 4). Mom issues a directive about the camera in line 09 with "Let's go put- $>>$ no no no $<<$ don't touch." With this turn she first attempts to return to play by starting a play-related directive, but then self-repairs and issues a directive concerning 
the video camera. Walter protests in line 10 with "no no w-". Mom issues another directive in line 11 with "Go play with the train okay $\ddot{i}$, in an attempt to get Walter to not orient to the camera and instead start playing. Walter then mentions the camera by giving a suggestion about its placement with "What if you put it up he:re." (line 12), and after no response "It can see us." (line 14). Mom and Walter then negotiate the placement of the camera (lines 15-24) and then begin playing with the trains (lines 25-26).

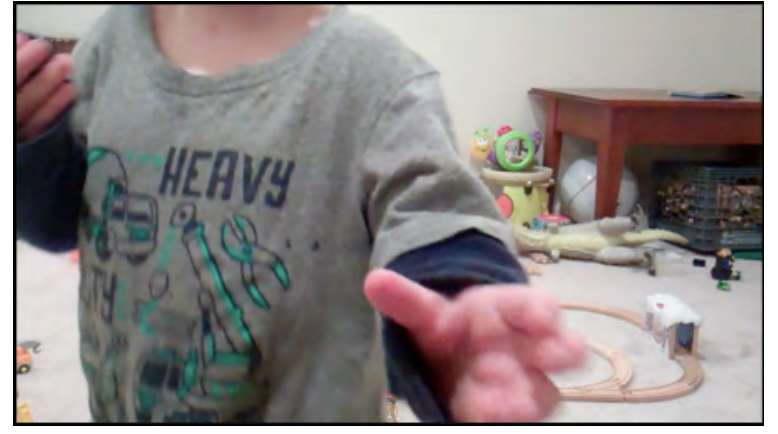

Figure 4. Walter reaches for the video camera.

In this instance, Mom's action of turning on the camera triggers Walter's orientation to it. In all of the instances where a child's orientation occurs after a parent turns on the camera, the children's orientations to the camera are almost immediate, demonstrating that it is the action of the parent orienting to the camera (by turning it on) that triggers the child's orientation.

Instances in which parents approach the camera were also included in this type of orientation and were those in which the parent moved or reached toward the camera. These three subtypes of "interacts with camera" are a result of the parent acting as a co-researcher (Given et al., 2016) and having responsibility for setting up the video camera in order to capture their children's interactions.

Talks about camera. Parents also issued directives to their children related to the presence of the video camera. For example, in extract 08, Jackson (8) and Shyla (5) are playing with playdough at the kitchen table while Mom is nearby but not in view of the camera. Mom issues a series of directives to Shyla in lines 05-06 and 10.

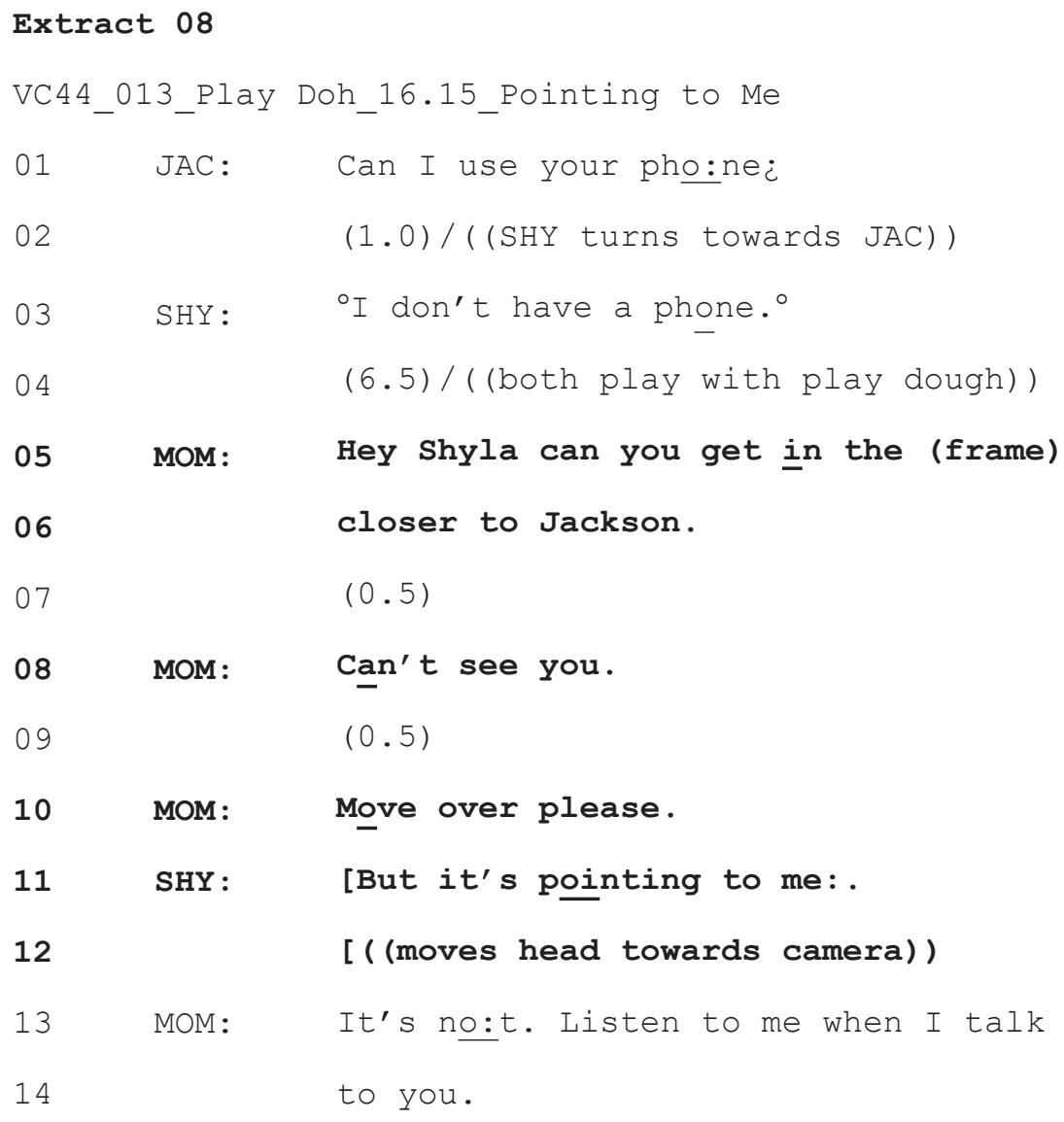




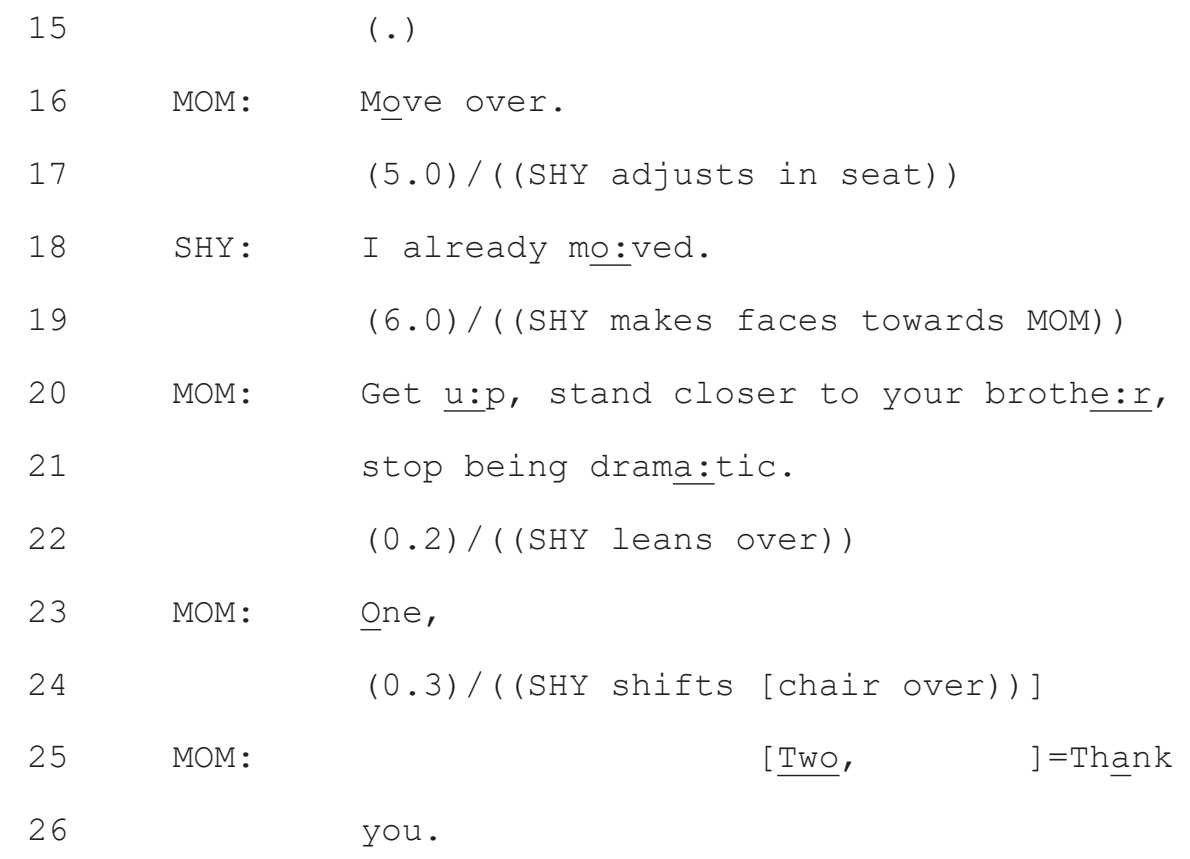

In lines 05-06, Mom issues a request to Shyla for her to move into the frame of the video camera with "Hey Shyla can you get in the (frame) closer to Jackson." With this request Mom makes the presence of the video camera relevant in the interaction; it is because of its presence that she makes the request. After no response, Mom explains that the video camera cannot see Shyla (line 08) with "can't see you.", referring to the video camera's inability to capture Shyla at that moment. After no response, in line 10 Mom issues a directive to Shyla with "Move over please." This functions as an upgrade from her previous request (Craven \& Potter, 2010). In lines 11-12, Shyla then orients to the video camera, arguing "But it's pointing to me:", while gesturing towards the video camera (see Figure 5). Here she treats Mom's directive as unnecessary, arguing that if the camera is pointed at her, then presumably it can see her. In lines 13-23 Mom and Shyla argue about Shyla moving, to which she finally concedes in line 24.

This subtype of orientation is also unique to parents, due to parents' role as co-researchers with responsibility for ensuring that the children are in view of and not playing with or disregarding the presence of the video camera. Since all parents were given the cameras and recording instructions, these orientations are a reflection of the parents' awareness of their responsibility as a coresearcher and providing adequate data for the researchers.

No preceding sibling or parent orientation. In 37 of the 102 instances of a child's orientation to the video camera, there were no evident orientations to the video camera by the other family

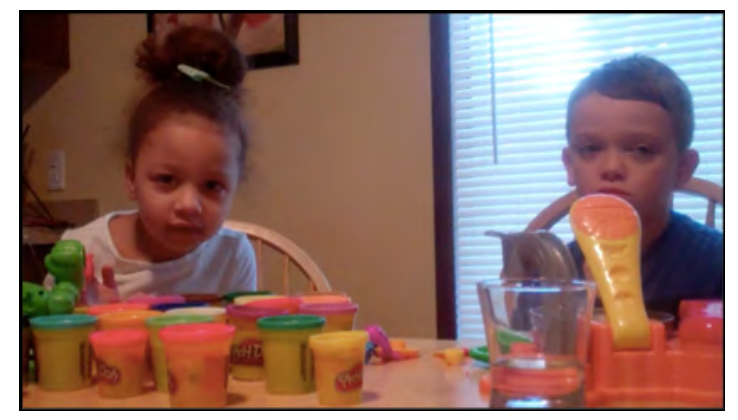

Figure 5. Shyla orients to the camera after Mom issues a directive. members present immediately preceding the child's orientation. In these instances, the children oriented to the video camera seemingly independently of the actions of others. For example, in extract 09, Mom, Dad, Valerie, Nathan, and Amanda are eating dinner. After looking at the camera for some time (lines 11-21), Amanda mentions the camera in line 28. 


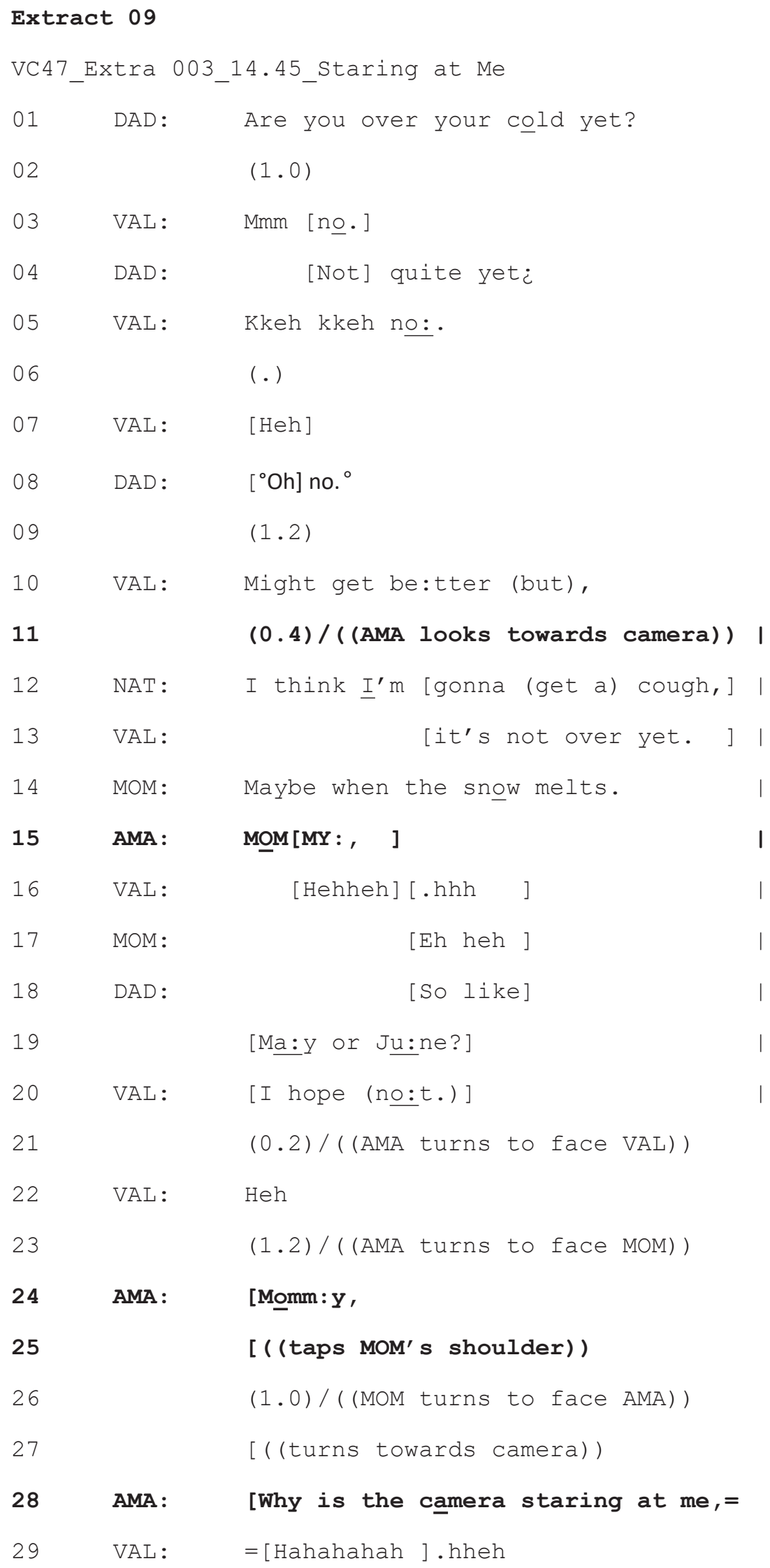




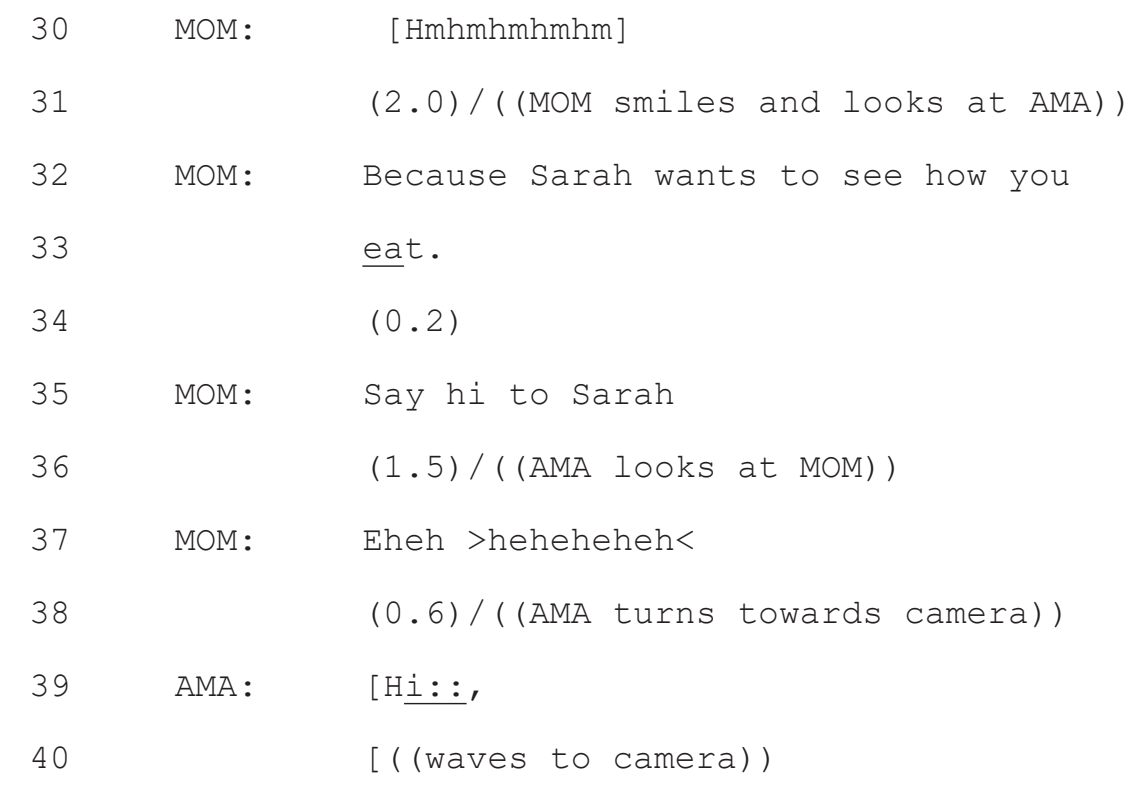

In line 11, Amanda looks toward the camera (continuously until line 21), while the rest of the family talks about Valerie's cold. In line 15, Amanda summons her Mom with, "MoM[MY:", but the family continues talking. In lines 24-25, Amanda summons again with "Momm:y,", this time tapping Mom on the shoulder. In line 26 Mom turns to face Amanda and in line 27 turns to face the camera. In line 28 Amanda asks, "Why is the camera staring at me,=". Mom responds with "Because Sarah ${ }^{5}$ wants to see how you eat." (lines 32-33), giving an explanation for the presence of the video camera. In this case, there is no preceding orientation to the video camera by any of the other family members, thus Amanda's orientation appears to be unprompted.

Children's orientations to the video camera that are not preceded by a sibling or parent orientation challenge the assumption that children are not aware of or influenced by the presence of the video camera during recordings. Although they represent a minority of the instances of child orientations in our data, the fact that they exist demonstrates that there may be an ongoing awareness of the video camera during recordings of everyday family life, or at the very least moments in which the mere presence of the video camera can cause children to outwardly speculate about its presence.

\section{Discussion}

This study analyzed 3- to 6-year-old children's orientations to the video camera in a corpus of recordings of everyday family interactions. Although the majority of video recordings did not include young children's orientations to the video camera, the majority of children in the target age range oriented to the video camera at least once. The average number and duration of children's orientations to the video camera were low, and the average total time spent orienting to the camera was short in comparison with the average length of video recordings families provided. Consistent with prior research (Antal et al., 2015), these findings support the assertion that participant reactivity is common in video recordings of young children but in most cases does not make up a substantial portion of the recorded talk and action.

Contrary to what other researchers have asserted (e.g., Häggman-Laitila et al., 2010; O’Shannessy, 2014; Rosenstein, 2002), the children in this study did not quickly become accustomed to the presence of the video camera. Instead, we found that orientations to the video camera occurred not only at the beginning of videos, but also throughout the recordings. Furthermore, while some children oriented to the video camera infrequently, for others, orienting 
to the video camera was not an "occasional moment of awareness" (Heath et al., 2010, p. 48) but instead a recurring activity throughout the recordings, becoming an activity in and of itself. For example, one child oriented to the video camera 10 times in a single video recording. The variety in the prevalence of children's orientation to the camera reinforces the need for researchers to examine participant reactivity in their own data in order to determine the extent of its influence (Heath et al., 2010).

Our findings demonstrate that children and their parents oriented to the video camera in a variety of ways: they talked about the camera, engaged in camera-directed talk and/or action, and interacted with the camera. While these higher-level categories of orientations to the video camera are consistent with those previously identified (e.g., Antal et al., 2015; Given et al., 2016; Speer \& Hutchby, 2003), our analysis offers a more in-depth categorization of the subtypes of orientations displayed by children than that offered by prior research, based on our inductive analysis of the data. That is, our analysis has revealed a broader variety of talk and/or actions that children engage in related to their awareness of the presence of the video camera than those discussed in prior research. This expands our understanding of the ways in which young children orient to the camera, creating a more comprehensive picture of participant reactivity in video recordings used in research.

Consistent with Antal et al.s (2015) work in medical contexts, the most common type of orientation to the video camera exhibited by the children was talking about the camera. However, in our study this was closely followed by camera-directed talk and/or actions, a type of orientation that occurred infrequently in Antal et al. (2015). Additionally, interacting with the camera was not identified as an orientation in Antal et al. (2015). Cameradirected talk/and or actions and, to a lesser extent, interacting with the camera were identified in Given et al's (2016) work, which, like the present study, involved video recordings collected by parents in the home. This indicates that the types of behaviours children engage in when orienting to the camera may be different depending on the setting in which the video recordings take place.

We also found that in the majority of instances of a child's orientation to the video camera, a parent and/or sibling first oriented to the video camera in some way. Thus, it appears that the majority of the children's orientations to the camera were triggered in some way. However, in just over a third of the instances of a child's orientation to the video camera, there were no evident orientations to the video camera by another present family member immediately prior to the child's orientation. These orientations that seemingly occur "out of the blue" offer additional support for the assertion that the video camera does not necessarily fade from participants' attention as they become used to its presence, as some researchers have argued (e.g., Heath et al., 2010; Knoblauch et al., 2012), but that some children may maintain an ongoing awareness of its presence.

\section{Limitations}

The findings of our analysis of young children's orientations to the video camera in recordings of family interactions are limited by the way in which the data was collected. That is, our findings are applicable to video recordings obtained in the home, with parents choosing when and where to collect such recordings with minimal researcher guidance. Thus, our findings may not be generalizable and/or transferable to other contexts in which young children's interactions are video recorded, such as when the researcher is present during video recording, or when such recordings are undertaken in a lab setting where the presence of the camera might be less noticeable. Additionally, there was variation in the children's prior awareness of the presence of the video camera and/or its purpose as part of the research study. In some orientations to the video camera, it is clear that the child is not aware of either the presence and/or purpose of the video camera (e.g., Extracts 6 and 9), whereas in other orientations the children appear to be aware of both the video camera's presence and purpose of recording their activities 
(e.g., Extracts 2, 5 and 7). Differences in children's awareness of the presence of the video camera and its research purpose may have influenced participant reactivity and may also limit the generalizability/transferability of the findings.

\section{Implications for researchers}

Projects that make use of parents as co-researchers may need to address head-on issues of parents recording "constructed activities designed to meet the project's needs" (Given et al., 2016, p. 4). In moving forward in research on families and children, some practical future implications have arisen out of this study. For example, it may be useful to give parents explicit instructions about how best to record family interactions in such a way as to reduce children's orientations to the camera, including suggestions for reducing their own orientations to the video camera while recording is underway, as parent and sibling orientations preceded children's orientations in the majority of cases in our data. It may also be prudent to provide parents with a script or set of suggestions for explaining the presence and purpose of the video camera to their children, which may help to reduce children's orientations to the video camera that involve questioning its presence.

Additionally, it is important to consider what implications orientations to the video camera have when analyzing video-recorded data. For instance, in our own analyses drawing on this collection, it is important for us to consider how orientations to the video camera may affect the other types of talk and action present in the data. Researchers who, along with Heath et al. (2010), assert that participant reactivity subsides once participants become accustomed to the video camera have advocated for discarding the first few minutes of a recording or, when a series of recordings are possible, the first few recordings in their entirety, to avoid the effects of participant reactivity on the remaining data (e.g., Elder, 1999; Gross, 1991; Happ, Sereika, Garrett, \& Tate, 2008). However, in cases such as ours where participant orientations to the video camera occur throughout some video recordings, alternative approaches must be used. For example, researchers may want to consider excluding portions of relevant data that occur in close proximity to orientations to the video camera.

\section{Future research}

The factors influencing young children's orientations to the video camera are not fully explored in this study. Future investigations should include a consideration of characteristics such as children's age. For example, Antal et al's (2015) study found that younger children oriented to the video camera more often than older children. Although analysis of orientations to the video camera by age is outside the scope of this study, it is interesting to note that five of the six children who did not orient to the video camera at all in our data were 3 years of age. Future work should also examine other factors that might have an impact on children's propensity to orient to the video camera. For example, it might be fruitful to examine if asking parents to provide children with a detailed explanation of the presence and/or purpose of the video camera and/or allowing children to play with the camera to reduce its novelty have an impact on participant reactivity.

Additionally, future work could focus on those orientations that are not immediately preceded by a family member's orientation to the video camera. These specific orientations could be analyzed in more detail in order to understand more about these seemingly serendipitous orientations to the camera. Such orientations could be analyzed sequentially; that is, in cases where the child's orientation to the camera did not immediately follow another's orientation to the camera, the video recordings could be analyzed in full to determine what else, if anything, might have caused the child's orientation. 


\section{Conclusion}

Researchers who make use of naturalistic observation via video recordings are divided on the influence the video camera has on the authenticity of the talk and actions these recordings capture (Lomax \& Casey, 1998; Speer \& Hutchby, 2003). In our data, not all children oriented to the video camera, and those who did, did so briefly. However, orientations to the video camera were displayed by the majority of the children in our study and included a wide variety of talk and actions. These findings indicate that while video recording may be less obtrusive than the presence of a researcher conducting in-person observation, the act of video recording may still influence children's interactions with their family members in the home. The orientations to the video camera analyzed in this study consisted entirely of talk and actions that would presumably not have occurred if the camera were not present.

Instead of viewing these orientations as evidence of the inauthenticity or unnaturalness of our data, we choose to consider such orientations part of the "ordinary social activities" (Sidnell \& Stivers, 2013, p. 33) of young children and their families that our work seeks to describe. By treating these orientations to the video camera as we would any other observable phenomenon of interest, we have provided evidence, not only of children's ongoing awareness of the video camera's presence in their homes, but also their understanding of how the camera works. This unanticipated area of inquiry was only made visible by the affordances of video-recorded data, demonstrating the power of this "microscope" (Aarsand, 2016, p. 91) in studying young children's social interactions. 


\section{References}

Aarsand, P. (2016). Children's media practices: Challenges and dilemmas for the qualitative researcher. Journal of Children and Media, 10(1), 90-97. https://doi.org/10.1080/17482798.2015.1121894

Antal, H., Hossain, M. J., Hassink, S., Henry, S., Fuzzell, L., Taylor, A., \& Wysocki, T. (2015). Audio-video recording of health care encounters for pediatric chronic conditions: Observational reactivity and its correlates. Journal of Pediatric Psychology, 40(1), 144-153. https://doi.org/10.1093/jpepsy/jsu046

Barriage, S., \& Searles, D. K. (2015, November). Astronauts and sugar beets: Young girls' information seeking in family interactions. Paper presented at the 78th Association for Information Science \& Technology Annual Meeting, St. Louis, Missouri. https://doi. org/10.1002/pra2.2015.145052010027

Craven, A., \& Potter, J. (2010). Directives: Entitlement and contingency in action. Discourse Studies, 12(4), 419-442. https://doi. org/10.11772F1461445610370126

Dunn, J. (2005). Naturalistic observations of children and their families. In S. Greene \& D. Hogan (Eds.), Researching children's experience (pp. 87-101). Thousand Oaks, CA: SAGE.

Elder, J. H. (1999). Videotaped behavioral observations: Enhancing validity and reliability. Applied Nursing Research, 12(4), $206-209$. https://doi.org/10.1016/S0897-1897(99)80273-0

Given, L. M., Winkler, D. C., Willson, R., Davidson, C., Danby, S., \& Thorpe, K. (2016). Parents as coresearchers at home: Using an observational method to document young children's use of technology. International Journal of Qualitative Methods, 15(1), 1-9. https://doi.org/10.11772F1609406915621403

Glaser, B. G., \& Strauss, A. L. (1967). The discovery of grounded theory: Strategies for qualitative research. New Brunswick, NJ: AldineTransaction.

Greene, S., \& Hill, M. (2005). Researching children's experience: Methods and methodological issues. In S. Greene \& D. Hogan (Eds.), Researching children's experience (pp. 1-21). Thousand Oaks, CA: SAGE.

Gross, D. (1991). Issues related to validity of videotaped observational data. Western Journal of Nursing Research, 13(5), 658-663. https:// doi.org/10.1177/019394599101300511

Häggman-Laitila, A., Seppänen, R., Vehviläinen-Julkunen, K., \& Pietilä, A.-M. (2010). Benefits of video home training on families' health and interaction: Evaluation based on follow-up visits. Journal of Clinical Nursing, 19, 3504-3515. https://doi.org/10.1111/j.13652702.2010.03241.x

Happ, M. B., Sereika, S., Garrett, K., \& Tate, J. (2008). Use of the quasi-experimental sequential cohort design in the study of patientnurse effectiveness with assisted communication strategies (SPEACS). Contemporary Clinical Trials, 29(5), 801-808. https://doi. org/10.1016/j.cct.2008.05.010

Heath, C., Hindmarsh, J., \& Luff, P. (2010). Video in qualitative research: Analyzing social interaction in everyday life. Thousand Oaks, CA: SAGE.

Hepburn, A., \& Bolden, G. (2017). Transcribing for social research. London, UK: SAGE.

Heritage, J. (1989). Current developments in conversation analysis. In D. Roger \& P. Bull (Eds.), Conversation: An interdisciplinary perspective (pp. 21-47). Clevedon, UK: Multilingual Matters.

Heritage, J., \& Stivers, T. (1999). Online commentary in acute medical visits: A method of shaping patient expectations. Social Science and Medicine, 49(11), 1501-1517. https://doi.org/10.1016/S0277-9536(99)00219-1

Jefferson, G. (1978). Sequential aspects of storytelling in conversation. In J. Schenkein (Ed.), Studies in the organization of conversational interaction (pp. 219-248). New York, NY: Academic Press.

Kidwell, M. (2013). Interaction among children. In J. Sidnell \& T. Stivers (Eds.), The handbook of conversation analysis (pp. 511-532). Oxford, UK: Wiley-Blackwell. 
Knoblauch, H., Schnettler, B., \& Raab, J. (2012). Video-analysis: Methodological aspects of interpretive audiovisual analysis in social research. In H. Knoblauch, J. Raab, H. Soeffner, \& B. Schnettler (Eds.), Video-analysis methodology and methods: Qualitative audiovisual data analysis in sociology (pp. 9-26). Frankfurt, Germany: Peter Lang.

Laurier, E. \& Philo, C. (2012). Natural problems of naturalistic video data. In H. Knoblauch, J. Raab, H. Soeffner, \& B. Schnettler (Eds.), Video-analysis methodology and methods: Qualitative audiovisual data analysis in sociology (pp. 183-192). Frankfurt, Germany: Peter Lang.

Lomax, H., \& Casey, N. (1998). Recording social life: Reflexivity and video methodology. Sociological Research Online, 3(2). Retrieved from http://www.socresonline.org.uk/3/2/1.html

McKechnie, L. (2000). Ethnographic observation of preschool children. Library \& Information Science Research, 22(1), 61-76. http:// dx.doi.org/10.1016/S0740-8188(99)00040-7

Moylett, H. (2014). Observing children to improve practice. In T. Maynard \& S. Powell (Eds.), An introduction to early childhood studies ( $3^{\text {rd }}$ ed.; pp. 227-242). Thousand Oaks, CA: SAGE.

O'Shannessy, C. (2014). Researching children's acquisition of sociolinguistic competence. In J. Holmes \& K. Hazen (Eds.), Research methods in sociolinguistics: A practical guide (pp. 304-324). Chichester, UK: Wiley Blackwell.

Pellegrini, A. D. (2013). Observing children in their natural worlds: A methodological primer. New York, NY: Psychology Press.

Penner, L. A., Orom, H., Albrecht, T. L., Franks, M. M., Foster, T. S., \& Ruckdeschel, J. C. (2007). Camera-related behaviors during video recorded medical interactions. Journal of Nonverbal Behavior, 31, 99-117. https://doi.org/10.1007/s10919-007-0024-8

Rideout, V. (2014). Learning at home: Families' educational media use in America. A report of the Families and Media Project. New York, NY: The Joan Ganz Cooney Center at Sesame Workshop.

Rosenstein, B. (2002). Video use in social science research and program evaluation. International Journal of Qualitative Methods, 1(3), 22-43. https://doi.org/10.11772F160940690200100302

Searles, D. K., \& Barriage, S. (2018). "What does curious even mean do you know?": Orientations to word meanings in family interactions. Journal of Pragmatics, 134, 57-69. https://doi.org/10.1016/j.pragma.2018.06.013

Semeniuk, Y. Y., \& Riesch, S. K. (2011). Analysis of participant reactivity in dyads performing a videotaped conflict-management task. ISRN Nursing, 2011, 1-6. http://dx.doi.org/10.5402/2011/596820

Sidnell, J., \& Stivers, T. (2013). The handbook of conversation analysis. Oxford, UK: Wiley-Blackwell.

Speer, S. A., \& Hutchby, I. (2003). From ethics to analytics: Aspects of participants' orientations to the presence and relevance of recording devices. Sociology, 37(2), 315-337. https://doi.org/10.1177/0038038503037002006

Tudge, J., \& Hogan, D. (2005). An ecological approach to observations of children's everyday lives. In S. Greene \& D. Hogan (Eds.), Researching children's experience (pp. 102-122). Thousand Oaks, CA: SAGE.

\section{(Endnotes)}

$1 \quad$ All names are pseudonyms.

2 Screenshots of video recordings are included with permission

$3 \quad$ Heritage and Stivers (1999) discuss the use of "online commentary" in medical consultations.

4 Although Nathan's orientation to the video camera is not our focus because he is not in the target age range, it is interesting to note his orientation to the video camera in this extract. He treats Amanda's actions as something that the "people at the university" will see, and implicitly then, something that she might not want them to see.

5 Here Mom is referring to one of the researchers. 